\title{
Domestic Free-Range Pig Genetic Resources in Southern Africa: Progress and Prospects
}

\author{
Tinyiko Edward Halimani ${ }^{1}{ }^{(0)}$, Obvious Mapiye ${ }^{2}$, Tawanda Marandure ${ }^{2}{ }^{(}$, Diedre Januarie ${ }^{3}$, \\ Venancio Edward Imbayarwo-Chikosi ${ }^{1}$ (I) and Kennedy Dzama ${ }^{2, *}$ \\ 1 Department of Animal Science, University of Zimbabwe, P. O. Box MP167, Mt Pleasant, Harare 0001, \\ Zimbabwe; tinyiko.halimani@gmail.com (T.E.H.); vichikosi@gmail.com (V.E.I.-C.) \\ 2 Department of Animal Science, Stellenbosch University, Private Bag X1 Matieland 7602, South Africa; \\ oomapiye@gmail.com (O.M.); tawanda@sun.ac.za (T.M.) \\ 3 Department of Agricultural Research and Training, Ministry of Agriculture, Water and Fisheries, \\ Windhoek 9000, Namibia; Deidre.Januarie@mawf.gov.na \\ * Correspondence: kdzama@sun.ac.za
}

Received: 23 November 2019; Accepted: 3 January 2020; Published: 7 February 2020

\begin{abstract}
Pig genetic resources in Africa originate from different regions and were introduced through several migration pathways. Genetic analysis has shown a strong phylogeographic pattern, with pigs on the eastern parts showing a high frequency of alleles from the Far East while the ones on the western parts show a strong European influence. This highlights the influence of trade routes on the genetic legacy of African pigs. They have, however, since adapted to the local environments to produce unique populations with unique attributes. Most of the pigs are now reared in resource-constrained smallholdings under free-range conditions. They are largely owned by women who spread ownership of the resource through kinship networks. Very little work has been done to characterize, conserve, and sustainably utilize pig genetic resources in Southern Africa. The risk status of the breeds together with population numbers, distribution, and other attributes are largely unknown. This paper proposes several strategies for the sustainable utilization of the pig genetic resources: A market-driven in situ conservation program and two complementary ex situ strategies. In addition, the possibility of community-based breed improvement programs is discussed. It was concluded that genetic characterization of domestic free-range pig populations should be a supreme priority.
\end{abstract}

Keywords: diversity; conservation; animal genetic resources; domestic pigs; southern Africa

\section{Introduction}

Pig populations are estimated be highest in Nigeria at 4.86 million, followed by Uganda (1.55 million), South Africa (1.54 million), Cameroon (1.35 million), and the Democratic Republic of Congo (1 million) [1]. There are several breeds and populations of pigs in Southern Africa, including commercial, nondescript, and feral, which have been introduced to the region through various pathways [2]. According to archeological evidence, imported pigs were used by passing Portuguese travelers, and more recently, by Chinese trading ships passing South African shores as a medium of barter exchange with local populations [3]. Other authors make reference to the last phase of introduction, which began in the 16th to 17th century when European breed types were introduced $[1,4]$. According to the Domestic Animal Diversity Information System (DAD-IS) [2], all the Southern African Development Community (SADC) countries, except the Comoros Islands, have the three major international breeds (Large White, Landrace, and Duroc). The Large White was first recognized as a distinct breed in England in 1884 [4]. The Landrace were originally developed in Denmark before being exported to various countries from 1949 [4]. The Duroc was developed in the USA and has become 
important as terminal sires in many countries [5]. The first Duroc pigs were imported into South Africa from Canada in 1980 primarily for crossbreeding purposes [4]. The region's pig genetic resources are also composed of several local or domestic free-range pig breeds with various names and attributes $[1,3]$. Early pastoralists in southern Africa found the domestic free-range pig unsuitable for a nomadic lifestyle while religious taboos, diseases, and habitat favored alternative types of livestock, such as cattle, sheep, and goats [1,4]. Domestic free-range pigs are well adaptable to local harsh conditions and this makes them important genetic resources, which can be conserved by utilization during the current era of climate change [6]. Threats to these genetic resources are well documented. According to Pilling [7], these threats can be classified into the following: Disasters and emergencies that lead to livestock mortality and restocking; disease epidemics and their control measures [4]; inappropriate breeding management strategies, and policies, which may lead to breed substitution and inadvertent loss of animal genetic resources; changing production systems and livelihoods, including economic growth, changes in culture, and, cross-cutting issues, such as climate change, which influence changes in feed and water availability; as well as emerging diseases. Additional threats also relate to inadequate policy and legal frameworks. For example, only $24.4 \%$ of African countries have reported the risk status of their animal genetic resources (AnGR), with even fewer countries supplying information on gene banks. It should be noted here that these two statistics are important indicators that constitute tier 1 (or core statistics) for Sustainable Development Goals (SDG 2; indicators 2.5.1 and 2.5.2). The available literature shows that 32 out of 71 breeds with known risk status are at risk. Applying this proportion to the remaining 703 reported livestock breeds would mean approximately 218 additional breeds are at risk. Lack of knowledge about the status of a breed is also a threat since it, concomitantly, includes a lack of breed characterization and inventory information.

Very little work has been carried out to characterize domestic free-range pigs in southern Africa. To date, the only SADC country with a complete plan for the management of AnGR as of 2019 is South Africa [7]. While the African Union Inter-African Bureau for Animal Resources (AU-IBAR) has developed a tool and portal for characterization of the continent's animal genetic resources, there has been very little effort by governments to allocate resources for that exercise [8]. The little work shows inadequate coverage of the populations and countries and the work is largely fragmentary and not well coordinated $[1,2,6]$. Therefore, poor characterization of domestic free-range pigs in southern Africa could hamper the possibility of mapping the distributions, population status, and diversity $[2,6]$, and more importantly, the role of these animals in human livelihoods [4,9]. In addition, little effort has been made to take advantage of more advanced techniques that are increasingly becoming cheaper, such as single nucleotide polymorphism (SNP) arrays [5].

One of the major constraints in conserving pig genetic resources in southern Africa is the lack of market participation of the majority of pig farmers [3], who keep small herds mainly for subsistence [4]. The major barriers to market participation are production constraints, information asymmetry, underdeveloped markets and support infrastructure, limited finance and other resources, and inadequate knowledge [4]. In addition, 'marketing systems [that serve smallholder farmers] are generally exploitative, collusive and economically inefficient' [10]. It is important to note that attaching a market value to a genetic resource is one of the easiest ways of conserving it. There are, however, certain breeds that do not have an immediate market value but are important as a store of option value, which is the benefit derived from safeguarding an asset for the option of using it at a future date-especially in response to changes in the production environment (changes in consumer taste, new diseases, and climate change among others [11]. This is not new, as there is evidence of such use of genetic resources to respond to adverse climate change in the past. The current review aims to discuss the origins and major constraints to the development of domestic free-range pig genetic material and to suggests strategies for the sustainable utilization of the pig genetic resources. 


\section{Origins and Description of Domestic Free-Range Pigs in Southern Africa}

Archaeological records show that the domestic free-range African pig originated from the Iberian between the third and seventh centuries and is roughly the same in all African countries, where it is known under different names [4]. In South Africa, it is known as Kolbroek, Somo in Mali, Busia pigs in Kenya, Bakosi in Gabon, West African Dwarf pig in Nigeria, Ashanti Dwarf pig in Ghana, Bush pig in Togo, and Mukota pigs in Zimbabwe [1]. A previous study by Halimani et al. (2012) [12] on domestic free-range pig populations in southern Africa based on different microsatellite loci similarly revealed a lack of substructure in the pig populations, validating the general similarity in commonly reported phenotypes. Sufficient genetic variation was, however, estimated for pig populations in Ghana and South Africa that can support genetic improvement for many growth and carcass traits in the breed [10,13]. Mujibi et al. (2018) [14] observed a significant introgression of genes from international commercial breeds into the Busia pigs in Kenya. Following various periods of utilization in South Africa, molecular data describing levels of diversity in these breeds are not available.

The domestic free-range breed in southern Africa is characterized by a small narrow frame size resting on relatively long legs and a short forehead with an elongated snout [4]. The breed rarely weighs more than $60 \mathrm{~kg}$ at 12 months of age, even under optimum rearing conditions [15]. Other phenotypic characteristics include a straight tail, and medium swept-back small ears carried horizontally or semi-erect. The skin is often dark, sometimes pie gray or red but rarely white [8]. The coat is variable; sometimes with formed long, coarse hairs, which almost hide the skin, with a strip of longer hair along the spine [8]. The main attributes of domestic free-range breeds are hardiness, foraging ability, heat tolerance, high fertility, good mothering ability, good quality meat, tolerance to endemic diseases and parasites, and adaptation to low management levels [4]. They are docile in nature and can survive by scavenging around homesteads, on a high fiber diet often supplemented with kitchen and/or vegetable waste [4]. The well-established adaptations to prevailing environmental and management conditions exhibited by domestic free-range animal populations represent valuable genetic resources for improving breeds and the efficiency of animal production. Domestic free-range populations may add potential characteristic genetic variation, which could be valuable to producers in supplying new diversity for the improvement of commercial lines [16]. However, domestic free-range pigs were long regarded as unsuitable for intensive commercial breeding because of their slow growth and inadequate meat production [17].

An absence of genetic improvement programs for smallholder pigs has long-term consequences. The domestic free-range pigs in Southern Africa have a slower growth rate than exotics, their major strength being adaptive traits that give them an advantage in low-intensity management smallholder systems [9]. Invariably, the genetic heritage of domestic free-range pigs is constantly threatened by genetic erosion caused by some indiscriminate crossbreeding with exotic breeds [14]. There are a few pig genetic and phenotypic characterization studies. The populations, genetic structure, attributes, and risk status have not been fully studied. The studies themselves lack coordination. What is particularly important is the near absence of government and private organizations in these efforts [8]. Food and Agriculture Organization's animal genetic resource database, the Domestic Animal Diversity-Information System, does not present information on numbers and genetic structure. The development of sound genetic improvement programs based on domestic free-range pigs requires information on preferred genetic parameters for traits of economic importance. In the literature, there are few, if any, reports on genetic parameters for growth and carcass traits in domestic free-range pig populations in southern Africa.

\section{Status of Domestic Free-Range Pig Production in Southern Africa}

Pig ownership in southern Africa is inclusive of all genders, with a slightly higher number of female owners $[4,6]$. The dominance of female owners and the spread of pigs within the gender is based on kinship networks that lead to assistance in the care of pigs and the sharing of genetic resource [1]. In addition, women may be default keepers of livestock since they care for families in the rural communities while men seek wage labor in urban areas [18]. Also, this could be because 
many domestic free-range pigs are small sized compared to other animals like cattle and are kept in the backyards, hence they are relatively easy to look after [6]. Women's selection criteria are different from those of men and may ultimately determine if the families remain livestock keepers or not. They choose animals that are easy to manage and are generally disease tolerant, which is not likely to increase their workload given that most of their time is taken up by the 'reproductive economy', which usually does not feature in economic analysis and agricultural policy. While the number of people employed in agriculture is decreasing overall, the proportion of women in agriculture is increasing [18]. The role of women in the maintenance and sustainable use of pig genetic resources needs to be recognized (and rewarded) in any strategies regarding the conservation of this resource.

\section{Sustainable Utilization and Conservation of Pig Genetic Resources in Southern Africa}

Smallholder pig owners who hold most of the genetic diversity face the following constraints. In terms of production, domestic free-range pig farmers tend to keep small numbers of pigs [1]. This allows them to match the animals to the available resources [9]. The farmers are vulnerable to shocks and lack access to modern production technology. The low numbers may lead to inbreeding [19] and vulnerability to disasters. Interestingly, the resource-constrained production systems seem better and more resilient than intensive pig production systems in Africa. Lekule and Kyvsgaard [20] cite three reasons for this apparent contradiction: Lower fixed costs and inputs compared to intensive production, access to kitchen waste that can be used to supplement a few scavenging pigs, and pigs having other functions in traditional systems that make their production worthwhile. Unfortunately, the factors that contribute to the resilience of these production systems also act as buffers that keep the systems in a low-level equilibrium that is difficult to upscale. In addition, there is a food-versus-feed conflict as a result of pigs sharing the same major feed ingredients that are used by humans for food.

Farmers usually do not have access to information about production, markets, feeds, etc. that would improve production. Pigs are also single-product animals unlike cattle and goats. A scarcity of natural, physical, financial, human, and social assets impacts the farmer's decision-making process [21]. Obviously, poverty will impact many aspects of production, including access to loans, information, drugs, and other resources [7]. Collective action is a useful tool for any activity, including management of animal genetic resources [22]. Smallholders are not involved in the structured selection of pigs neither do they have concrete breeding programs. Free-range production systems offer limited disease surveillance, monitoring, and biosecurity options. There are several studies $[12,20,23]$ that demonstrate this. Free ranging also increases contact with feral pigs, which may be a contributing factor to the outbreaks of African swine fever [13]. Other issues include overarching constraints that are external to the production system, which include conflicts, globalization, population growth, changing consumer tastes, religious taboos, developments in science and technology, and climate change. These will obviously impact conservation and use of AnGR in some way [16].

Sustainable conservation of animal genetic resources requires a thorough characterization of the attributes and possible uses for a breed and the development of niche markets for their products Utilization of local pig genotypes in communal areas has the potential to increase food security, reduce poverty, and improve the livelihoods of the resource-poor farmers. The Convention on Biological Diversity (CBD) defines sustainable use as the use of components of biological diversity in a way and at a rate that does not lead to the long-term decline in biological diversity, thereby maintaining its potential to meet the needs and aspirations of present and future generations [15]. The CBD also recognizes 'the vital role that women play in the conservation and sustainable use of biological diversity and affirming the need for the full participation of women at all levels of policy-making and implementation for biological diversity conservation'.

Strategies that enhance in situ conservation of genetic resources while directly benefitting the smallholder farmers are often more preferred. In situ conservation allows the animals to keep adapting to changes in their environment while performing other important roles, such as ecosystem services. The next best strategy is to use ex situ conservation either in vivo or in vitro. In vivo ex situ conservation 
will still require a market for the animals. This will entail the use of public research stations and farms (and any other breeders) to maintain conservation and commercial herds. There is a need to establish a gene bank for AnGR to preserve species that are threatened with a loss of genetic diversity to allow for repopulation, expanding the genetic base of a breed as well as research. This also has the additional benefit of protecting the resources from disasters and disease outbreaks [24]. The objective is to maintain maximum genetic diversity using few individuals. In the United States of America, cluster analysis is used to evaluate pedigree data to identify 'families' of animals within a breed to be a sample for conservation [24]. Table 1 below summarizes the likely interventions and timelines to achieve sustainable conservation and utilization of pig genetic resources in Southern Africa.

The easiest route to conservation and sustainable use is the development of markets for the pig genetic resources. Market development can be done in the following ways:

1. Investing in infrastructure and institutions: According to Barrett [25], market access is both a cause and a consequence of development. There is a need for public investment in institutional and physical infrastructure necessary to ensure broad-based, low-cost access to competitive and well-functioning markets.

2. Farmer organization: Collective action enables farmers to access markets while reducing transaction costs of purchasing inputs, market information, and new technologies [22]. Farmer organizations also provide an opportunity for recording and breed improvement since records can be kept and breeding objectives can be set. Barrett [25] states that market participation is the same as adoption of new technologies and should be evaluated as such. Organizing farmers helps in the adoption of this 'technology' en masse. Besides, farmers keep relatively small herds so organization will help aggregate the excess stock for sale.

3. Policy interventions: Several workers $[22,26,27]$ emphasize the importance of policy intervention in promoting both conservation and market access by smallholder farmers. There is a need to develop a set of policies that incentivize farmers to produce local pigs. In addition, the public sector needs to build institutions that support the conservation, utilization, and improvement of the domestic free-range breeds. There should be an effort to harmonize policy on conservation and marketing in the region. These policies should recognize the role played by women in maintaining these resources.

4. Development of products and markets: Köhler-Rollefson [28] reported eight cases of marketing domestic free-range livestock products in different communities, countries, and circumstances. In all cases, there were interventions of different nature (ranging from policy to the development of new products) along the value chain. There is a need to explore ways of either developing niche markets, new products, or contract farming to enable the introduction of neglected genetic resources into the market.

Breed improvement is closely linked to marketing. However, the development of breeding programs should consider the fact that the breeding goals of smallholders are much more multifaceted compared to the commercial pig farmers who focus on a few traits of economic importance, such as fast growth rates, larger carcasses, disease tolerance, etc. Goals for smallholders include aesthetic (color and patterning), behavioral aspects (temperament, mothering ability, foraging behavior, herdability, and any other aspects that minimize labor on livestock), adaptability, and the ability to survive on low management levels [28]. Rege et al. [16] highlight the need 'to improve, produce, deliver and sustain genotypes appropriate for the objectives of the target poor livestock keeper/producer'. This will obviously incorporate indigenous knowledge in the breeding programs. Several possible schemes have been proposed, including sire rotation or loan schemes, nucleus-based programs run by the public sector and linked to community-level multipliers, and other community-based programs where selection is done at the community level [16]. There is an opportunity to use recent advances in technology, especially assisted reproductive technologies and genomics, to quicken the process without a loss of diversity $[5,29]$. There is also a need to build breeding societies around the neglected breeds. 
Table 1. Identification of the key activities, actors, and needs for sustainable utilization and conservation of pig genetic resources.

\begin{tabular}{|c|c|c|c|c|}
\hline Variable & Activities & How & When & Who \\
\hline \multirow[t]{3}{*}{ Food and nutrition security } & $\begin{array}{l}\text { Increase the number of pig } \\
\text { growers }\end{array}$ & $\begin{array}{l}\text { To conduct a needs assessment study followed by various } \\
\text { awareness campaigns } \\
\text { Facilitate information dissemination among farmers and } \\
\text { between farmers and extension through ICTs }\end{array}$ & 2020-2025 & $\begin{array}{l}\text { Researchers, Extension, } \\
\text { Government, Farmers } \\
\text { NGOs }\end{array}$ \\
\hline & $\begin{array}{l}\text { Reduced mortality } \\
\text { (Better reproductive efficiency) }\end{array}$ & $\begin{array}{l}\text { Improve animal health and housing management. } \\
\text { Farmer capacity building programs }\end{array}$ & $2020-2025$ & $\begin{array}{l}\text { Researchers, Extension, } \\
\text { Government, Farmers } \\
\text { NGOs }\end{array}$ \\
\hline & $\begin{array}{l}\text { Improve environmental and } \\
\text { public health }\end{array}$ & $\begin{array}{c}\text { Farmer training } \\
\text { Establishing biosecurity structures to control zoonotic diseases }\end{array}$ & 2020-2025 & $\begin{array}{l}\text { Researchers, Extension, } \\
\text { Government, Farmers } \\
\text { NGOs }\end{array}$ \\
\hline \multirow[t]{2}{*}{ Income generation } & Identification of current market & $\begin{array}{l}\text { Improve product quality and quantity and timing as well as } \\
\text { addressing price and policy issues } \\
\text { Conducting a qualitative and quantitative value chain analysis } \\
\text { Create niche market } \\
\text { Constructing processing facilities }\end{array}$ & 2020-2025 & $\begin{array}{l}\text { Researchers, Extension, } \\
\text { Government, Farmers } \\
\text { NGOs }\end{array}$ \\
\hline & $\begin{array}{c}\text { Farmer organization for } \\
\text { collective resource mobilization }\end{array}$ & $\begin{array}{l}\text { Incentive group farming and contract farming } \\
\text { Facilitate credit support for the farmer groups in production } \\
\text { Creating small farmer abattoirs }\end{array}$ & $2020-2025$ & $\begin{array}{l}\text { Researchers, Extension, } \\
\text { Government, Farmers } \\
\text { NGOs }\end{array}$ \\
\hline
\end{tabular}




\section{Conclusions}

The review shows that domestic free-range pigs have remained an important resource to rural people in southern Africa. However, characterization and inventorying on the animals' genetic resources are still incomplete and the available information is fragmentary and not coordinated. Even, the uses of these domestic free-range pig genetic resources are not well documented across the region. Production of the animals is low, and this is largely constrained by limited resources. However, smallholder free-range systems seem to be more resilient and sustainable despite the lower inputs and biosecurity measures. Most domestic free-range pigs are owned and looked after by women. This makes women an important stakeholder in any policy intervention around sustainable utilization and conservation of domestic free-range pig resources.

Future market development complemented by well-planned ex situ conservation programs could be effective strategies towards in situ conservation of pig genetic resources. This has the added benefit that the pigs will continue to serve other functions depending on farmer objectives. Also, to meet market demands and elevate the productivity of the farmers, there is a need for breed improvement without a loss of genetic diversity. Thus, suggested programs should always incorporate indigenous knowledge systems and smallholder farmer breeding objectives. The farmers have much more multifaceted breeding objectives that include aesthetic, behavioral, suitability for religious or cultural roles, and adaptive traits. Therefore, to improve characterization, genetic utilization, and conservation of the local pig resources, there is a need for a coordinated southern Africa regional policy framework that is backed by adequate resources.

Author Contributions: T.E.H., O.M., T.M. and D.J. conceptualized the research topic and objective. T.E.H. and O.M. wrote the original draft. Editorial inputs; O.M., T.M., V.E.I.-C. and K.D. All authors read and approved the final manuscript.

Funding: This research received no external funding.

Acknowledgments: The authors acknowledge the support received from AU-IBAR and the University of Stellenbosch who organized the AnGR colloquium (Southern Africa farm animal genetic resources colloquium: Intersecting innovation, food security and livelihoods. Held from 17th to 19th of July 2019 at Stellenbosch University, Wallenburg Centre, STIAS, Marais Road, Stellenbosch) at which parts of this paper were presented.

Conflicts of Interest: The authors declare no conflict of interest.

\section{References}

1. Bester, J.; Kusel, U.S. Early domesticated animals in South Africa. In Proceedings of the 4th Global Conference on Conservation of Domestic Animal Genetic Resources, Lallitpur, Nepal, 17-21 August 1998.

2. Swart, H.; Kotze, A.; Olivier, P.A.S.; Grobler, J.P. Microsatellite-based characterization of Southern African domestic pigs (Sus scrofa domestica). S. Afr. J. Anim. Sci. 2010, 40, 121-132. [CrossRef]

3. Quin, P. Foods and Feeding Habits of the Pedi. S. Afr. Med. J. 1959, 38, 969-971.

4. Plug, I.; Badenhorst, S. The Distribution of Macromammals in Southern Africa over the Past 30,000 Years as Reflected in Animal Remains from Archaeological Sites; Transvaal Museum Monograph Number 12; Ultra-litho (Ply) Ltd.: Pretoria, South Africa, 2001; ISBN 0907990185.

5. Rothschild, M.; Ruvinsky, A. The Genetics of the Pig, 2nd ed.; CABI: London, UK, 2002; ISBN 1845937562, 9781845937560 .

6. Giuffra, E.; Kijas, J.M.H.; Amarger, V.; Carlborg, O.; Jeon, J.-T.; Andersson, L. The Origin of the Domestic Pig: Independent Domestication and Subsequent Introgression. Genetics 2000, 154, 1785-1791. [PubMed]

7. Pilling, D. Threats to animal genetic resources for food and agriculture-approaches to recording, description, classification and analysis. Anim. Genet. Resour. 2010, 47, 11-22. [CrossRef]

8. African Union-Interafrican Bureau for Animal Resources. Local African Pig; AU-IBAR: Nairobi, Kenya, 2015.

9. Taylor, G.; Roese, G.; Hermesch, S. Breeds of pigs-Landrace Origin and History Breed Characteristics. Available online: http://www.dpi.nsw.gov.au/primefacts (accessed on 16 November 2019).

10. Chimonyo, M.; Dzama, K. Estimation of genetic parameters for growth performance and carcass traits in Mukota pigs. Animal 2007, 1, 317-323. [CrossRef] [PubMed] 
11. Halimani, T.E.; Muchadeyi, F.C.; Chimonyo, M.; Dzama, K. Opportunities for conservation and utilisation of local pig breeds in low-input production systems in Zimbabwe and South Africa. Trop. Anim. Health Prod. 2013, 45, 81-90. [CrossRef] [PubMed]

12. Halimani, T.; Muchadeyi, F.; Chimonyo, M.; Dzama, K. Some insights into the phenotypic and genetic diversity of indigenous pigs in southern Africa. S. Afr. J. Anim. Sci. 2012, 42, 507-510. [CrossRef]

13. Ayizanga, R.; Kayang, B.; Adomako, K. Genetic diversity of some Ghanaian pigs based on microsatellite markers. Livest. Res. Rural Dev. 2016, 28, 24.

14. Mujibi, F.D.; Okoth, E.; Cheruiyot, E.K.; Onzere, C.; Bishop, R.P.; Fèvre, E.M.; Thomas, L.; Masembe, C.; Plastow, G.; Rothschild, M. Genetic diversity, breed composition and admixture of Kenyan domestic pigs. PLoS ONE 2018, 13, e0190080. [CrossRef] [PubMed]

15. Kanengoni, A.T.; Dzama, K.; Chimonyo, M.; Kusina, J.; Maswaure, S.M. Influence of Level of Maize Cob meal on Nutrient Digestibility and Nitrogen Balance in Large White, Mukota and LW $\times$ M F 1 Crossbred Pigs; Cambridge University Press: London, UK, 2002; Volume 74, pp. 127-134.

16. Van Marle-Köster, E.; Visser, C. Genomics for the advancement of livestock production: A South African perspective. S. Afr. J. Anim. Sci. 2018, 48, 808-817. [CrossRef]

17. Penrith, M.L.; Vosloo, W. Review of African swine fever: Transmission, spread and control. J. S. Afr. Vet. Assoc. 2009, 80, 58-62. [CrossRef] [PubMed]

18. Plug, I. Origin of South African livestock and their potential role in the industry. In Livestock Production Systems: Principles and Practice; Maree, C., Casey, N.H., Eds.; AGRI Development Foundation: Pretoria, South Africa, 1993; pp. 11-13.

19. Food and Agriculture Organization. The State of the World's Animal Genetic Resources for Food and Agriculture; Rischkowsky, B., Pilling, D., Eds.; Food and Agriculture Organization: Rome, Italy, 2003; Available online: http://www.fao.org/3/a-a1250e.pdf (accessed on 8 November 2019).

20. Madzimure, J.; Chimonyo, M.; Zander, K.K.; Dzama, K. Potential for using indigenous pigs in subsistence-oriented and market-oriented small-scale farming systems of Southern Africa. Trop. Anim. Health Prod. 2013, 45, 135-142. [CrossRef] [PubMed]

21. Thutwa, K.; Chabo, R.; Nsoso, S.J.; Mareko, M.; Kgwatalala, P.M.; Owusu-Sekyere, E. Indigenous Tswana pig production characteristics and management practices in southern districts of Botswana. Trop. Anim. Health Prod. 2019. pre-print. [CrossRef] [PubMed]

22. Halimani, T.E.; Muchadeyi, F.C.; Chimonyo, M.; Dzama, K. Pig genetic resource conservation: The Southern African perspective. Ecol. Econ. 2010, 69, 944-951. [CrossRef]

23. Anderson, S.; Centonze, R. Property Rights and the Management of Animal Genetic Resources. World Dev. 2007, 35, 1529-1541. [CrossRef]

24. Ibeagha-Awemu, E.M.; Peters, S.O.; Bemji, M.N.; Adeleke, M.A.; Do, D.N. Leveraging available resources and stakeholder involvement for improved productivity of African livestock in the era of genomic breeding. Front. Genet. 2019, 10, 1-21. [CrossRef] [PubMed]

25. Zanga, J.; Chimonyo, M.; Kanengoni, A.T.; Dzama, K.; Mukaratirwa, S. A comparison of the susceptibility of growing Mukota and Large White pig genotypes to infection with Ascaris suum. Vet. Res. Commun. 2004, 27, 653-660. [CrossRef] [PubMed]

26. Dzama, K.; Ngwerume, F.N.; Bhebhe, E. Future prospects in pig improvement in Zimbabwe. In Proceedings of the International Symposium on Livestock Production through Animal Breeding and Genetics, Sheraton Hotel, Harare, Zimbabwe, 10-11 May 1995; p. 144.

27. Köhler-Rollefson, I. Invisible Guardians - Women Manage Livestock Diversity; Food and Agriculture Organization: Rome, Italy, 2012.

28. Lekule, F.P.; Kyvsgaard, N.C. Improving pig husbandry in tropical resource-poor communities and its potential to reduce risk of porcine cysticercosis. Acta Trop. 2003, 87, 111-117. [CrossRef]

29. Gabre-Madhin, E. A Market for All Farmers: Market Institutions and Smallholder Participation; Proceedings of the conference Agriculture for Development in Sub-Saharan Africa; Centre of Evaluation for Global Action, University of Carlifonia: Berkeley, CA, USA, 2009.

(C) 2020 by the authors. Licensee MDPI, Basel, Switzerland. This article is an open access article distributed under the terms and conditions of the Creative Commons Attribution (CC BY) license (http://creativecommons.org/licenses/by/4.0/). 